\title{
Certa unidade no sincrético: Considerações sobre educação, reeducação e formação de professores na "Psicologia Pedagógica" de L. S. Vygotsky
}

\author{
Gisele Toassa \\ Universidade Federal de Goiás
}

\begin{abstract}
Resumo
Este trabalho, que cotejou uma das edições brasileiras da "Psicologia Pedagógica" com o original em russo, visa a ressaltar algumas contribuições originais de tal livro, publicado por L. S. Vygotsky em 1926. Discutem-se as preocupações do autor com uma escolarização ativa e livre, abordada em uma conjuntura de crise e reestruturação da psicologia. O livro apresenta características de uma "síncrese" de ideias, posições e influências divergentes. Com análise de ideias básicas e objetivos presentes no material, este artigo busca extrair a "unidade no sincrético" pela qual o autor, em linguagem mecanicista, pensa a educação como formação humana, e o educador, como artista ou lutador, valorizando o papel do meio social em sua efetivação e antecipando as noções de drama e crise do desenvolvimento.
\end{abstract}

Palavras-chave: Vygotsky; educação; psicologia da educação; formação de professores.

\begin{abstract}
Some unit in miscellaneous: Considerations about education, reeducation and teachers' formation in the book "Pedagogical Psychology" by LS Vygotsky. This study, which compared a Brazilian edition of the "Pedagogical Psychology" with the original in Russian, aims to highlight some original contributions of this book, published by LS Vygotsky in 1926. This article discusses some of the author's concerns with an active and free education, taken up in a psychology marked by crisis and restructuration. Being affected by this conjuncture, the "Pedagogical Psychology"'s content is characterized for a "miscellany" of ideas, positions and divergent influences. With analysis of basic ideas and objectives presented in the material, this article seeks to extract some "unity in miscellaneous" by which the author, in mechanistic language, argues about education as human formation and educator, as an artist or fighter, valuing the environment's role in its effectiveness, and also works in notions similar to "drama" and "crisis" of development.
\end{abstract}

Keywords: Vygotsky; education; educacional psychology; teachers trainning.

\section{Resumen}

Una unidad en el sincrético: Consideraciones sobre educación, reeducación, y formación de docente en la "Psicología Pedagógica" de LS Vygotski. Este estudio, que cotejó una de las ediciones brasileñas de "Psicología Pedagógica" con el original ruso, tiene como objetivo poner de relieve algunas de las aportaciones originales de este libro, publicado por LS Vygotsky en 1926. Se discuten las preocupaciones del autor con una educación activa y libre, en un contexto de crisis y reestructuración de la psicología. El libro presenta las características de un "síncrese" de ideas, posiciones e influencias divergentes. Con el análisis de las ideas y objetivos presentes en el material de base, este artículo pretende extraer la "unidad en lo sincrético" en que el autor, en lenguaje mecanicista, piensa la educación como formación humana, y el educador, como artista o combatiente, valorando el papel del medio social. También las nociones de drama y crisis del desarrollo se discuten en este artículo.

Palabras clave: Vygotsky, la educación, psicología de la educación, formación docente.

$\mathrm{O}$ livro documenta a época em que Vygotsky, ainda em Gomel, lecionara em uma escola de formação de professores para crianças entre 10 e 15 anos (Blanck, 1926/2003; van der Veer \& Valsiner, 2001). Concluído quando seu autor não contava mais de 28 anos, é o mais extenso dos trabalhos do autor sobre questões educacionais. Supõe-se que a "Psicologia Pedagógica" foi finalizada no primeiro ano de trabalho de Vygotsky no Instituto de Psicologia de Moscou 
(1924). Este artigo consiste em estudo teórico que, procurando preservar o vigor do texto original, dissertará sobre noções básicas (como reação, comportamento e experiência) e suas relações com as de educação, reeducação e papel do educador. Um dos objetivos é desvelar a semântica de alguns dos principais conceitos da "Psicologia Pedagógica" que, a despeito de sua imaturidade teórica, ecletismo e problemas de composição decorrentes tanto do seu caráter de compêndio quanto de sua rápida elaboração - vem sendo pouco comentado em suas contribuições originais e valor histórico ${ }^{1}$, foco essencial ao presente texto.

\section{Estrutura e proposta do livro}

É pertinente considerar a "Psicologia Pedagógica" um texto de divulgação científica, documentando o talento de seu autor para a seleção de trechos interessantes de autores capitais para a fundação da psicologia, como W. Wundt (e Escola de Leipzig), W. James e H. Münsterberg. A "Psicologia Pedagógica" é exemplo da concepção Vygotskyana sobre a primazia do interesse e da curiosidade no plano da aprendizagem/ desenvolvimento - tendo um estilo notavelmente dialógico. Mesmo relatos experimentais, ao invés de apresentar-se com densidade acadêmica, são investidos de fluência narrativa, apresentando anedotas sobre os mais diversos temas, de modo a deixar-nos a impressão, como assinala Blanck (1926/2003, p. 16), de que seu escritor é um jovem sábio. Vygotsky filosofa a partir das psicologias já existentes, adotando professores de crianças e adolescentes como interlocutores, e, como adversário principal, a pedagogia tsarista, tratada com ironia desdenhosa, ao longo de um texto transbordante de otimismo e confiança na revolução educacional soviética. Entre os textos publicados no Ocidente, também é o mais jovem no qual o autor aproximase do marxismo - aproximação que deixou marcas tanto nos objetivos quanto no conteúdo do livro, senão tanto em sua forma propedêutica. O material recende otimismo juvenil - jovem autor de uma jovem Revolução. O livro inaugura um ambicioso projeto de psicologia: inspirado por Trotski, Vygotsky tinha por finalidade criar o lay out da psicologia em relação à cultura e ao super-homem (Rückriem citado por Yasnitsky, 2011, p. 63), desenvolvida em suas bases epistemológicas em "O significado histórico da crise na psicologia" (1926).

A "Psicologia Pedagógica", na tradução publicada pela Artmed (Vygotsky, 1926/2003), compõe-se de apresentações de comentadores e do tradutor; prólogo de Vygotsky; três capítulos com conceitos básicos; 14 com temas em psicotécnica e a conclusão, denominada “A psicologia e o professor". Definindo a psicotécnica como psicologia aplicada (às organizações, à educação, à medicina, à economia, à estética, etc.), a psicologia pedagógica corresponde ao vínculo entre psicotécnica e psicologia da cultura, embora Vygotsky não defina a ideia de cultura, que mal aparece no restante do livro - e quando surge, assemelha-se a produções mais maduras (Vygotski, 1935/1995), referindo-se ao contraste entre os domínios humano e animal, nova e especificamente humana forma de adaptação dos instintos ao ambiente (Vygotsky, 1926/2003, p. 92), que modifica a própria estrutura de nosso comportamento. O termo é muito próximo à noção de experiência social/histórica, tal qual veremos mais adiante.

Como afirma Blanck (1926/2003): "Vygotsky escreve sem eufemismos". Um exemplo do sincretismo ético-político de seu discurso pode ser constatado nos pontos em que debate o papel das mulheres na educação e na sociedade: ora incorre em sexismo, como vemos na sua aprovação da ideia de Münsterberg (de que a educação não devia estar progressivamente sob encargo das mulheres), ora reconhece que é absolutamente necessário emancipá-las do quarteto filhos-cozinha-vestidos-igreja. Aproximar homens e mulheres era importante para dinamitar a visão deturpada e hiperssexualizada do gênero que, desde priscas eras, recebe a pecha de frágil e pouco inteligente ${ }^{2}$. Essa não era uma especificidade de Vygotsky: o clima revolucionário privilegiava a práxis em detrimento do rigor acadêmico, e nosso autor chegou a manifestar uma leitura equivocada e superficial sobre as características desejáveis em professores na conclusão do livro, não repetida em produções posteriores ${ }^{3}$.

O objetivo declarado de Vygotsky é deitar "vinho velho em odres novos" - ou seja, velhos autores, como James e Wundt, nos odres do pavlovismo. De fato, o vocabulário apresenta marcas da influência da ciência dos reflexos pavloviana, embora de modo menos presente do que essa ideia do autor nos levaria a presumir. Como se nota em texto por ele redigido três anos depois:

Criar novas palavras e denominações pareceu uma pretensão falsa, porque para descrever os fenômenos seria preciso utilizar o nome antigo e também o material anterior. Por isso, consideramos mais adequado decifrar em cada caso o verdadeiro conteúdo, tanto de um termo antigo quanto do próprio material (Vygotsky, 1926/2003, p. 35).

Vygotsky (1926/2003, p. 34) já visualizava a "crise da psicologia", caracterizada pela fragmentação e necessidade de mudanças estruturais, e não simples reformas lexicais: considera que o livro tem marcas da época de crise da psicologia na qual se elaborou, a qual contaminava a psicologia pedagógica, pois os problemas pedagógicos situavam-se no centro da nova psicologia. Ainda no prólogo do autor, notamos também a proposta de análise de velhos termos e materiais, além da tradução de ideias de outros autores na sua própria linguagem. Visa a dirigir para professores os "melhores produtos" da psicologia, acolhendo uma diversidade eclética: mesmo tradições teóricas profundamente divergentes como as de Thorndike e Freud convivem harmoniosamente no debate sobre os instintos.

Por vezes, é difícil identificar quando Vygotsky renova o velho ou simplesmente mantém intactos os velhos termos - haja vista que um dos mais importantes conceitos da Psicologia Pedagógica, "reação" (reaktsia - реакция) - apresenta-se tanto na velha psicologia de W. James (1900/2005) e Münsterberg (1916) como na nova, a reactologia de K. N. Kornilov, devedora de Pavlov. Todos esses autores são citados por Vygotsky, sendo James abordado em contexto francamente positivo, antes da crítica que lhe dirigiu Vygotsky no seu "Teaching about emotions" (Toassa, 2012). Segundo van der Veer \& Valsiner (2001), A. R. Luria nota que os jovens pesquisadores do Instituto de Moscou na esfera de influência de Kornilov, como ele próprio e Vygotsky, inseriam a palavra "reação" onde podiam. Mas as outras influências que identificamos parecem dispor tal palavra 
na condição de rio principal, formado por diversos afluentes.

As psicologias então existentes, bem como as ciências da atividade nervosa superior do início do século XX, são debatidas na "Psicologia Pedagógica", tornando indesejável a leitura do texto sem conhecimento da história da psicologia e de tais ciências (além de campos interdisciplinares afins), hoje reconfiguradas no enorme campo das neurociências ${ }^{4}$. As notas de Blanck a Vygotsky (2003) certamente auxiliam a compreender muitos desses problemas decorrentes das mais de oito décadas após a primeira edição do livro. Já outras - e reação talvez seja a principal - desenvolveram-se com a psicologia historicocultural, e não vem recebendo devida análise por parte dos comentadores. Basta reconhecermos que o Tomo III em russo contém o espantoso número de 492 ocorrências do radical reakts (реакц) e o Tomo II, 79 ocorrências ${ }^{5}$.

Em Vygotsky (1926/2003), o conceito de reação é vital para a ambição de restituir a psique ao comportamento, sem separar vivências/memórias/percepções (elementos constitutivos da ideia de psique que se configura no livro) da ação no mundo. Em obras mais maduras do autor desenvolve-se um dos poucos conceitos de consciência psicológica que implica os pólos da percepção e da ação, em um claro monismo materialista ${ }^{6}$. O termo reação proporcionou-lhe saída estratégica com relação à estreiteza do conceito de reflexo. A proposta do autor é restituir o cérebro ao comportamento - e à educação, a possibilidade de formação do estudante como aparato que reage, sendo a escola, grandioso aparelho de fechamento de vínculos, recurso criador de uma vida humana supranatural (pp. 192; 302). O texto exala, pois, entusiasmo marxista com o mundo da técnica no limiar de uma sociedade que universalizasse sua utilização. Notamos que nessa linguagem mecanicista, impregnada de Pavlov e Münsterberg, que ecleticamente coexiste com as ideias de dialética (filosófica) e drama/tragédia (teatral), há a noção de que a formação humana é campo de luta "intraorgânica" entre diversas tendências, não cabendo estreito determinismo (Blanck, 1926/ 2003). Na conclusão, o autor afirma que o desenvolvimento infantil assemelha-se à tragédia, processo de permanente desadaptação. Tratando do negativismo manifesto por certa criança, que se comprazia em recusar-se às demandas dos adultos: Esse negativismo é só um caso particular da manifestação de falta de adaptação geral que constitui uma característica básica da infância. No momento do nascimento e no decorrer de toda a infância, a criança é um organismo sumamente desadaptado, não-equilibrado com o ambiente. Por isso, ela sempre precisa de um equilíbrio artificial, com a ajuda dos adultos. Por isso, ela é o ser mais emocional e deve rir ou chorar, raramente permanece neutra, pois as emoções são pontos de desequilíbrio em nosso comportamento quando nos sentimos pressionados pelo meio ou quando triunfamos sobre ele. Devido a isso, a marca da tragédia nunca pode ser apagada dos processos de crescimento e da educação infantis, e o ingresso da criança à vida foi e sempre será um processo de dolorosa ruptura e de criação, de dilacerações e geração de tecidos. Bühler está totalmente certo ao dizer que "a transformação de nossas crianças em homens é o maior de todos os dramas do desenvolvimento". Como um dente que vai cortando a gengiva, a criança entra com dor e força na vida (Vygotsky, 2003, p. 205-206).
Na conclusão, Vygotsky também defende o processo criador como fundamento do trabalho pedagógico, donde concluímos que, se o autor compreende a escola qual aparato de criação de novas reações, isso certamente não se dá de maneira mecanicista (a despeito do vocabulário hegemonicamente empregado no livro), mas sim dialética, antecipando a noção de drama que se desenvolverá ao longo de sua obra (Delari Júnior, 2011). A "Psicologia Pedagógica" constitui-se em exemplo de como as ideias de um autor podem transcender as palavras dele.

\section{Reflexos, comportamentos e reações}

Vygotsky (1926/2003) considera prudente chamar reação às formas básicas do comportamento humano, "resposta do organismo provocada por qualquer estímulo" (p. 47). Reação e comportamento (povedenie - поведение, também presente em Vygotski, 1931/1995) são bastante difíceis de diferenciar no texto Vygotskyano. O reflexo é conceito estritamente fisiológico - a reação, conceito amplamente biológico, marcando o caráter de "resposta a estímulo" de certo movimento; o fato de que há respostas do organismo às modificações do meio. Dividese em três momentos (momenti - моменты - com subtítulo erroneamente traduzido como "componentes", página 47 de Vygotsky, 1926/2003):

1) Percepção das excitações originadas no meio (sensorial);

2) Elaboração da excitação nos processos internos do organismo - relacionado aos animais superiores e ao ser humano (central);

3) Ação de resposta decorrente dos processos internos, geralmente como movimento (motor).

Há trechos em que os termos "reação" e "comportamento" equivalem-se. Na página 48, por exemplo, Vygotsky (1926/2003) comenta que esses "componentes" (momenti) aparecem com formas cada vez mais encobertas, sendo preciso fazer uma análise complicada para revelar a natureza da reação. Nas formas mais complexas do comportamento, os três momentos são de difícil percepção. A inserção do ser humano na natureza adquire tintas poéticas no trecho:

O conceito de reação nos ajuda a incorporar o comportamento humano à longa série de movimentos biológicos de adaptação de todos os organismos, dos inferiores aos superiores; [ajudanos] a vinculá-lo aos fundamentos da vida orgânica na Terra, a descobrir as ilimitadas perspectivas para o estudo de sua evolução e a considerar o aspecto biológico do comportamento de forma mais ampla (Vygotsky, 1926/2003, p. 49).

O acúmulo de novas reações/comportamentos impregna-se de materialismo histórico - ainda pouco elaborado, pois só a edificação de um sistema psicológico propriamente Vygotskyano vai gerar uma apropriação consistente desse materialismo (que já percebemos na "Psicologia da Arte") - por meio da mediação do conceito de experiência (opit - опыт), bastante saliente no livro. O que Vygotsky (1926/2003, p. 63) denomina de "fator social", confere componentes totalmente novos à conduta do ser humano, sendo a experiência humana função complexa da experiência social da humanidade e seus diferentes grupos. Afirma o autor que: "o saber que não passa pela experiência pessoal não é saber” (Vygotsky, 1926/2003, p. 76). Nesse ponto, não há 
inconsistências entre a tradução da ARTMED e o original russo.

Na página 63, esboça-se síntese das categorias com que Vygotsky procura explicar toda "fórmula do comportamento do ser humano", embora de modo bastante resumido:

(1) Reações hereditárias;

(2) Reações hereditárias multiplicadas pela experiência pessoal (reflexos condicionados);

(3) Experiência histórica;

(4) Experiência social; e

(5) Experiência duplicada (consciência)

Mesmo as observações mais simples do comportamento animal ou humano levam-no a perceber que em sua composição há reações de várias origens (como inatas e adquiridas). Linguagem tão própria de uma psicologia impregnada de pavlovismo e darwinismo, que procura apontar direções para a superação das grandes restrições nas noções de "inato" e do "adquirido", mas se situa, ainda, nessa démarche biologicista, a se superar apenas com a estruturação da psicologia historicocultural e a ideia de sistema funcional. Porém, é interessante observar que mesmo as reações hereditárias, para Vygotsky, demandam participação do ambiente em seu desenvolvimento.

As duas primeiras categorias (reações hereditárias) são encontradiças também em outras espécies - como podemos verificar nas citações dos parágrafos anteriores - espécies bem distantes de nós na escala evolutiva. A experiência histórica refere-se a que, ao contrário de outros animais, temos história, utilizamos a experiência das gerações anteriores. A experiência social coletiva configura a relação que podemos estabelecer com a experiência de outras pessoas: posso conhecer o Saara ou saber sobre Marte pela mediação das reações condicionadas do pensamento ou da fala de pessoas que os conhecem de algum modo. A experiência duplicada é por Vygotsky relacionada à capacidade humana de prever os resultados do trabalho, orientando as reações nessa direção. A popular citação marxiana, que traça analogia entre as operações da abelha e do arquiteto (erroneamente traduzida como "pedreiro", em Vygotsky, 1926/2003) serve-lhe como fundamentação de tal ideia. A importância dela faz-se sentir no fato de que ela também abre artigo da mesma época, "A consciência como problema de psicologia do comportamento" (Vygotski, 1924-1934/1991a). A experiência duplicada parece-nos identificar-se com a ideia de consciência nesse trecho, sem se diferenciar consciência individual e social, embora se diferenciem experiência social e histórica da experiência individual.

Ao lado disso, há amplas observações sobre o papel do ambiente na experiência: "é importante frisar que o fator decisivo na formação da experiência pessoal é o ambiente. Justamente, a estrutura do ambiente cria e determina as condições das quais depende, em definitivo, a elaboração de toda a conduta individual" (Vygotski, 1924-1934/1991a, p. 54). Segundo Vygotsky, todas as reações humanas, desde o berço, possuem os elementos de todas as formas mais complexas de comportamento que levaram à descoberta da análise espectral, às campanhas de Napoleão ou à descoberta da América. Os elementos básicos para constituição da experiência pessoal estão presentes desde o berço, em uma aglomeração caótica, não-organizada. $\mathrm{O}$ crescimento que separa a conduta do adulto da infantil se reduz ao estabelecimento de novos vínculos e ao aumento de sua mútua coordenação.

A transformação dessa experiência social pela mediação da experiência pessoal, das vivências conscientes, é um trajeto indispensável na formação de novos sistemas de reação ou mudança dos sistemas de reação já existentes. Há, pois, um sistema de interconexão e constituição de diversas mediações que configuram uma impregnação do materialismo histórico no conceito de opit. A tentativa de acomodar psique e comportamento em um mesmo conceito tem na reação sua primeira expressão, sendo que o comportamento humano representa apenas uma de muitas possibilidades, em que um reflexo dominante, tendo vários subdominantes, triunfa na chamada "luta pelo campo motor comum".

\section{Conceito de educação e reeducação}

Apontando a influência de Blonski, afirma Vygotsky:

A educação pode ser definida como a influência e a intervenção planejadas, adequadas ao objetivo, premeditadas, conscientes, nos processos de crescimento natural do organismo. Por isso, só terá caráter educativo o estabelecimento de novas reações que, em alguma medida intervenham nos processos de crescimento e os orientem. Nem todos os novos vínculos que se fecham [formam] na criança, portanto, serão atos educativos (1926/2003, p. 82).

Noutros trechos do livro, Vygotsky também considera a intencionalidade inerente à educação (ideia afim à noção de "experiência duplicada", como vimos acima), aproximandose, neste ponto, da noção de Saviani (2008), filósofo marxista segundo quem este é "o ato de produzir, direta e intencionalmente, em cada indivíduo singular, a humanidade que é produzida histórica e coletivamente pelo conjunto dos homens" (1926/2003, p. 13). Potenciais influências esporádicas, não-sistematizadas ou aleatórias sobre o indivíduo em desenvolvimento, embora componham parte de sua experiência, não se qualificariam como educação (vospitanie - воспитание). É útil observar, também, que Vygotsky não previa coincidência entre educação e desenvolvimento/crescimento - desenvolver-se e crescer implicava estar sob influência de diversos meios (sredi) sociais, nem sempre de modo prolongado ou premeditado. Note-se que a edição de Vygotsky (1926/2003) traduz o termo russo sredá (среда) ora como "ambiente", ora como meio.

Em contraposição a isso, a educação era forma especial de influência, mediada por diversos níveis de elaboração da experiência. $\mathrm{O}$ autor também defende que a educação significa mudança da conduta herdada e inoculação de novas formas de reação (Vygotsky (1926/2003, p. 41), consistindo em "processo de reorganização social das formas biológicas de conduta" ( $p$. 34). Certa ordenação implica-se também na ideia de que educar significa organizar a vida do aprendiz, significa "processo de seleção social da personalidade externa" (p. 82). Embora, nesse trecho, o autor não se detenha na explicação da ideia de personalidade, podemos relacioná-la ao desempenho de papéis diversos pelo sujeito - como na brincadeira, em que a criança imagina ser bandido, soldado ou cavalo - evidenciando sua multiplicidade de potenciais e tendências, que os adultos tendem 
a subestimar. Mesmo caso para sua afirmação reiterada de que o professor é como o florista; o psicólogo, como botânico (p. 43). "A psicologia pedagógica é, justamente, a ciência sobre as leis de modificação do comportamento humano e sobre os meios de dominar essas leis" (p. 43).

É digno de nota que a ideia de mеio (sredá - среда) perpassa as considerações de Vygotsky sobre diversos temas, entre os quais se destaca o desenvolvimento humano. $\mathrm{O}$ autor rompeu de modo mais profundo com essas considerações dicotômicas sobre hereditariedade X ambiente também explorando a acepção de sredá como ambiente psíquico ou cultural e mental no qual o homem se insere, acepção vigente no idioma russo desde o século XVIII (Pequeno Dicionário Enciclopédico Brockhaus e Efron, citado em Vygotsky, 1935/2010). Vygotsky assinalou também a importância de considerar a influência do meio a cada momento da vida da criança: "o meio, no sentido imediato dessa palavra, modifica-se para a criança a cada faixa etária. Alguns autores dizem que o desenvolvimento da criança consiste na gradativa ampliação de seu meio.” (Vygotsky 2010, p. 683). Com essa afirmação, o autor revê observações já presentes na "Psicologia Pedagógica", texto que sustenta o desafio de educar observando a transição entre o "pequeno" e o "grande" mundo da criança - ou seja, entre o microcosmo da família e da escola e a sociedade socialista.

A consolidação da categoria vivência no processo pelo qual o meio influencia o desenvolvimento só vem a se caracterizar claramente em textos posteriores, bem como a noção de "situação social de desenvolvimento", que retrata, dialeticamente, a situação do indivíduo em sua singularidade, para além da mera soma esquizofrênica de interações com meios que não dialogam entre si. $\mathrm{O}$ fator biológico determinaria a base, o fundamento das reações herdadas, sobre as quais se constrói o sistema de reações aprendidas - determinadas pela estrutura do ambiente. “A educação é realizada através da própria experiência do aluno, que é totalmente determinada pelo ambiente; a função do professor se reduz à organização e à regulação de tal ambiente" (Vygotsky, 1926/2003, p. 77).

Analisando a tese de que qualquer meio social artificialmente criado inclui vínculos que se distinguem da realidade objetiva ${ }^{7}$, divergindo da vida - no que se tornaria, então, indesejável para educar para a vida - ele dispõe a meta da educação não como adaptação a um meio já existente, mas criação de um ser humano que olhe para além de seu meio: fabricação do novo homem revolucionário. Não é possível calcular ao certo quais elementos da vida predominarão no educando, segundo Vygotsky (1926/2003). E os elementos do meio podem influenciar de modo nocivo um organismo em crescimento, mutante e frágil, o que dota a escola de significação, organizando as influências dos adultos sobre as crianças. Afigura-se simplificado considerar, pois, a "Psicologia Pedagógica" como apologia da Escola Nova e da auto-educação. Posteriormente, o autor desenvolveu suas noções sobre o meio social, por exemplo, ao afirmar - mediante análise de contribuições de Hegel - que o ser humano descobre as leis da natureza para obrigá-la a seguir sua própria vontade (Vygotski, 1931/1995, p. 93). Hegel considerava a mediação como a propriedade mais característica da razão: sua astúcia consistiria em que a atividade mediadora permite aos objetos atuar reciprocamente uns sobre os outros de acordo com sua natureza e consumir-se no dito processo, não tomando parte direta nele, mas levando a cabo seu próprio objetivo. A relação da razão com a realidade externa se dá, pois, de modo indireto (p. 93). Não há transmissão direta, ou inculcamento de ideias no educando: apenas se tornando parte ativa do meio social é que esse meio pode produzir "zonas de desenvolvimento próximo", para empregar terminologia de Vygotsky (1935/2007).

O meio (sredá) social não é algo totalmente estático, rígido e invariável. E ainda, segundo Vygotsky, na realidade, não existe um meio único; ele se divide em fragmentos mais ou menos independentes e isolados entre si, que podem ser objeto da influência humana. O meio é sempre o meio social para o ser humano - pois, quando aparece como meio natural, estão presentes aspectos sociais; mesmos seres naturais, não humanos, são nomeados, ascendendo à esfera da linguagem. Somente de modo muito estrito é possível contrapor meio social e natural. Se entendermos o meio social como o conjunto das relações humanas, podemos compreender sua excepcional plasticidade, extensiva à educação. $\mathrm{Na}$ experiência pessoal, não surgem reações novas. Os elementos delas estão presentes, mas sem coordenação ou organização. $\mathrm{O}$ processo de crescimento se reduz ao estabelecimento de novos vínculos entre o mundo e o organismo, e ao aumento de sua mútua coordenação.

Tal como Blonski (Danilchenko, 1993), Vygotsky (1926/2003, p. 75) defende a "auto-educação": segundo ele, em última instância, só é possível educar a si mesmo, nossos movimentos são nossos professores. No organismo da criança transcorre a luta entre diferentes influências - nesse sentido, a educação sempre foi social, por mais antissocial que fosse o conteúdo de sua ideologia. Das escolas gregas à Idade Média e do Oriente, os que educavam não eram professores e preceptores, mas o meio (sredá) social escolar. Vygotsky valoriza uma escolarização ativa e livre, que englobasse as mais diversas esferas culturais na criação do homem novo. A escola não deveria levar o aluno a simplesmente perceber, passivamente (notamos, com essa afirmação, que o autor ainda não desenvolvera noções importantes sobre a percepção mediada, voluntária, transcendendo a recepção passiva de informações).

Outro conceito importante dentre as reflexões educacionais do autor é o de reeducação (perevospitanie - перевоспитание). Como observamos, só são "educáveis" os indivíduos em desenvolvimento. Quando se trata de adultos, devemos, segundo Vygotsky (1926/2003, p. 81), falar em reeducação, como reelaboração dos sistemas de reações já existentes termo que não se aplicaria apenas a "delinquentes" ou a "portadores de transtornos mentais", mas também, por exemplo, a treinamento profissional como datilografia ou taquigrafia. Em Vygotsky, lemos: "em todos os casos seria mais acertado falar precisamente de reeducação, porque, psicologicamente, estamos diante da formação de vários vínculos novos dentro de um sistema de comportamento previamente formado" (p. 81-82). Equívoco significativo de tradução está no termo "vários" do trecho acima, que precisaria ser substituído por "alguns" - tal como verificamos na tradução de Paulo Bezerra (Vygotsky, 1926/2001) - pois o original russo é nekotorii (некоторый).

Ao tratarmos de adultos, seria necessário falar em 
"reeducação", em reelaboração de alguns vínculos componentes de sistemas de reações já existentes. As pretensões de uma educação de adultos seriam, portanto, mais modestas? O trecho citado no parágrafo anterior nos induz a crer em tal restrição. Mas outras ocorrências de perevospitanie nos levam a concluir que o autor considerava possível, por exemplo, a reeducação do temperamento (a despeito das diferenças entre seus diversos tipos, sendo que eles não são igualmente sujeitos a essa reeducação), levando-nos à admissão de que o conceito de "reeducação" se aplica mesmo à influência sobre o temperamento, cujas raízes são herdadas. Aúnica condição para isso seria respeitar a lei geral das reações: é mais fácil a passagem das reações fracas às intensas, das formas passivas às ativas, do temperamento fleumático ao sanguíneo. Faltam-nos as bases bibliográficas de Vygotsky sobre essa "lei", que provavelmente compõe a reactologia de Kornilov.

Outras ocorrências do termo perevospitanie estão no Capítulo 15, “O comportamento anormal” (Vygotsky 1926/2003, p. 262-263), e no 19, “A psicologia e o professor” (p. 303). Elas se referem à reeducação das crianças de conduta psiconeurótica, sendo essa conduta relacionada à ocorrência de uma situação penosa na interação organismo-ambiente. Sua reeducação é possível com a promoção de novas inter-relações entre meio e criança. Se não é possível falar em “educação" nos adultos, a "reeducação" parece poder se aplicar a crianças e adultos, desde que haja prévia educação. Note-se que o processo de reeducação como reelaboração dos sistemas de reações já existentes não precisa ser necessariamente promovido por mediadores externos. No capítulo 19, ao comentar Zalkind, sustenta Vygotsky que os artistas podem tentar reeducar o estado de desconforto donde emerge a composição da obra. Quanto mais intenso o desconforto, quanto mais complexo o mecanismo psíquico do homem, mais naturais serão os ímpetos pedagógicos de que tais estados internos são dotados.

\section{O papel do educador}

Vygotsky dispõe indagações marxistas, compreendendo que, tal como outros trabalhadores, o professor é organizador e diretor da produção e parte de sua própria máquina ${ }^{8}$ (1926/2003, p. 76), faz um trabalho com dupla natureza, sendo o primeiro aspecto de seu papel cada vez mais importante, com a evolução da técnica. O professor é parte do mecanismo e está fora - perfaz unidade dialética com o meio. A escola caracteriza-se pela atividade de professores e alunos:

O professor desempenha um papel ativo no processo de educação: modelar, cortar, dividir e entalhar os elementos do meio para que estes realizem o objetivo buscado. O processo educativo, portanto, é trilateralmente ativo: o aluno, o professor e o meio existente entre eles são ativos (Vygotsky, 1926/2003, p. 79).

O processo não é uniforme, mas contém altos e baixos, assemelhando-se ao próprio crescimento físico. O professor aparece como regulador externo da atividade, antes de sua internalização pela criança - alguém que a orienta. Ainda que seja impotente quanto à sua influência sobre o aluno, é onipotente em sua influência indireta, como parte do meio social. Em metáfora escolanovista, para lembrar Facci (2009), Vygotsky (1926/2003, p. 76) sustenta que, como o agricultor, o professor influencia a germinação das plantas por meio das mudanças correspondentes no meio ambiente. Ao invés de fazer pelo aluno, não deve procurar substituir os livros, os mapas, os dicionários, mas sim incitar essas poderosas forças do meio, obrigando-as a servir à educação. O professor também se situa como força da natureza, verdadeiro lutador que visa a criar as condições para a formação de novos vínculos/novas reações.

Vygotsky (1926/2003) dedica a conclusão do livro a projetar, afinal, as características do novo professor para a sociedade socialista. Passando por citações de diversos autores, ressalta que o maior perigo na psicologia do professor consiste em que ele comece a se sentir como um "gramofone": o aspecto "maquínico" predomine sobre o papel "organizador" da educação (p. 296). Com isso, não se torna menos que um apóstolo da redundância, de certo modo temeroso do risco existente em emitir voz própria, cobrindo-se de elementos puramente secundários do conhecimento. As ideias do autor sobre o temperamento sustentam sua afirmação de que "aquele que não é ardente nem frio, mas só temperado, nunca poderá ser um bom professor" (p. 298).

Alternativa contra a redundância pedagógica seria que o professor não estivesse apenas um passo à frente do aluno, mas muito além dele. Sem tal distância, não seria possível levá-lo a caminhar, tropeçar e cair, sofrendo a dor de seus próprios machucados e escolhendo sua direção.

Além disso, comunicar - sem afetações esdrúxulas vivência do valor daquilo que é ensinado faz-se elemento fundamental do trabalho educativo. A redução do processo educativo a funções profundamente monótonas e insignificantes e o uso de castigos pervertia o professor, provocava-lhe neuroses muito mais do que no aluno ${ }^{9}$, simplificando-lhe as tarefas ao máximo. Vygotsky compara a nova pedagogia a uma arte verdadeira e complexa, de bases científicas (entre as quais se situava a ciência psicológica), que demandava formação de professores mediada por conhecimentos da matéria e técnica de seu trabalho, de espírito coletivo, vigor e elevação. Tintas utópicas - próximas do irrealizável - tingem as observações de que o professor deve permanecer em seu papel até o fim e, também, ser algo mais do que professor, profissão que deveria desaparecer em um futuro próximo. Seria possível, mesmo em uma sociedade revolucionária, proporcionar formação tão ampla a alguém?

O professor do futuro não será um instrutor, mas um engenheiro, um marinheiro, um militante político, um ator, um operário, um jornalista, um cientista, um juiz, um médico, etc. Isso não implica, porém, que tenha de ser um diletante em pedagogia. Na própria natureza do processo educativo, em sua essência psicológica, está implícita a exigência de um contato e de uma interação com a vida, que sejam o mais estreito possível (Vygotsky, 1926/2003, p. 300).

A citação reforça a ideia de que só a vida educa, e tanto mais forte será o processo educativo quanto mais ela penetrar na escola. Citando Münsterberg, Vygotsky sustenta que o professor deveria olhar o mundo de sua mesa de trabalho, as inquietações e alegrias da vida: o trabalho pedagógico orienta-se não em 
função da imitação, mas sim de criação coletiva de uma vida humana "supranatural", cujo objetivo seria refundar o homem. Neste aspecto, o ensino assemelha-se não só à arte, mas à guerra. Não é harmônico. $\mathrm{O}$ criador sempre pertence à raça dos desconformes, eis porque a educação não pode se limitar somente à razão. Para tais obstáculos e comoções deve haver afinidade entre educador e educando e proximidade nos sentimentos e conceitos: "a educação é um processo de permanente adaptação mútua de ambos os campos, em que o lado mais ativo, o que toma a iniciativa, por vezes é o dirigente ou o dirigido" (Vygotsky, 1926/2003, p. 303). Trocam-se vivências combativas na tensa luta do trabalho pedagógico: o professor, muitas vezes, ocupa solitária posição, empregando todos os seus elementos pessoais, experiência de sentimentos e pensamentos, além da vontade. Complexa é a condição psíquica do trabalho docente!

Exige-se do professor conhecimento exato das leis da educação - ele deve criar seu trabalho com base no conhecimento científico e não na inspiração. Ao mesmo tempo, deve ser um verdadeiro professor e não um linguista, um matemático etc. Condena-se o ideal do professor pautado na receptividade, doçura e desvelo. No capítulo 11: "O comportamento social e sua relação com o desenvolvimento da criança", Vygotsky projeta imagem trágica da infância, antecipando as noções de drama e crise do desenvolvimento, melhor desenvolvidas em seus trabalhos pedológicos, bem como a preciosa ideia de que não há propósito (ou teleologia) na natureza. Um pedagogoeducador não pode deixar de ser um artista, sendo um absurdo esperar que sua tarefa restrinja-se à pura razão. Educação e criação são trágicas por partirem do desconforto, do infortúnio, da falta de harmonia. Em citação talvez mais nietzschiana que materialista histórica:

Não se encontra em nosso caminho toda essa pedagogia que açucarava o "dourado tempo da serena infância" e adoçava com água de rosas o processo pedagógico. Pelo contrário, sabemos que o mais poderoso motor da educação é o aspecto trágico da infância, como a fome e a sede são inspiradoras da luta pela existência. Por isso, a educação não deve ocultar nem velar os duros traços do autêntico "desconforto" da infância, mas fazer a criança enfrentá-lo da forma mais aguda e frequente possível e estimulá-la a vencê-la. Ao mesmo tempo, a vida vai se revelando como sistema de criação, de permanente tensão e superação, de constante combinação e criação de novas formas de comportamento. Assim, cada ideia nossa, cada um de nossos movimentos e vivências constituem a aspiração a criar uma nova realidade, $o$ ímpeto para a frente, rumo a algo novo (Vygotsky, 1926/2003): A criação de novas reações no processo educacional deve ser orientada, pois, por uma ética libertadora com relação às formas sociais que deformavam e mutilavam a formação humana noutros tempos. A paixão socialista de Vygotsky atinge o clímax na última página do livro, quando, lembrando o "Manifesto Comunista" (Marx, 1848/2003), o autor dispõe sua própria versão de uma sociedade na qual a alimentação, sono, amor, jogo, trabalho e política, sentimentos e ideias humanas serão objeto da criatividade. O educador tornar-se-ia o verdadeiro criador do futuro (Vigotski, 1926/2003, p. 303).

\section{Considerações finais}

A "Psicologia Pedagógica” de Vygotsky (1926/2003) demarca tentativa de constituir campo intermediário entre a psicologia e educação, mostrando-se combinação de psicotécnica e psicologia da cultura. A noção de que a pedagogia encontra-se no limite entre as ciências que estudam fatos e as que estabelecem normas, enquanto que à psicologia pedagógica as normas não importam, é central no texto.

A "Psicologia Pedagógica" é, efetivamente, eclética, fazendo-se material de divulgação científica composto por ideias em parte já superadas, superação esta vislumbrada por seu próprio autor. A despeito desses problemas, adivinha-se "certa unidade no sincrético" nos três conceitos principais que aqui debatemos, os quais antecipam ideias posteriores da produção Vygotskyana. Neste sentido, as persistentes considerações de que o meio social escolar cria desenvolvimento, mas não nas condições em que se deseja (lembrando a noção de que na produção social da própria vida, os homens contraem relações determinadas, necessárias e independentes de sua vontade, em Marx, 1859/1999, p. 52), é um golpe na noção da educação como simples treinamento ou transmissão e faz jus à complexidade de um problema central da psicologia, a consciência individual. Projetando os predicados do professor revolucionário como "artista" ou "lutador", talha imagem atualíssima em tempos de massacre neoliberal e opressão institucional, tão característicos da educação brasileira, para lembrar o meio social analisado no grande clássico de Patto (2008).

\section{Referências}

Blanck, G. (2003) Prefácio. In L. S. Vygotsky (Org.), Psicologia pedagógica (pp. 15-32). São Paulo: Martins Fontes. (Texto original publicado em 1926).

Danilchenko, M. G. (1993) Pavel Petrovich Blonsky. Prospects: The quarterly review of comparative education, 23, 1/2, 113-124.

Darwin, C. (2008) A origem das espécies (Tomo I). São Paulo: Escala.

Delari Junior, A. (2011) Sentidos do "drama" na perspectiva de Vygotsky: Um diálogo no limiar entre arte e Psicologia. Psicologia em Estudo, 16(2), 181-197.

Dicionário Yandex (s/d) Recuperado de http://slovari.yandex.ru/

Engels, F. (2007) A origem da família, da propriedade privada e do estado. São Paulo: Escala. (Trabalho original publicado em 1884)

Facci, M. G. D. (2009) Para além do escolanovismo de Vygotsky: Compreendendo o trabalho do professor na obra Psicologia Pedagógica. In: M. G. D Facci; S C. Tuleski \& S. M. S. Barroco (Orgs.), Escola de Vygotsky: Contribuições para a Psicologia e a educação (pp. 87-106). Maringá: EDUEM.

James, W. (2005) Talks to teachers on psychology: And to students on some of life 's ideals. Boston: Geo. H. Ellis CO. Recuperado de http://www.gutenberg. org/files/16287/16287-h/16287-h.htm (Trabalho original publicado em 1900)

Kollontai, A. (2000) A nova mulher e a moral sexual. São Paulo: Expressão Popular. (Trabalhos originais publicados entre 1918-1921)

Marx, K. (1999) Para a crítica da economia política. In Marx. (pp. 25-56). São Paulo: Nova Cultural. (Trabalho original publicado em 1859)

Marx, K. (2003). Manifesto comunista. São Paulo: Instituto José Luiz e Rosa Sunderman. (Trabalho original publicado em 1848)

Münsterberg, H. (1916). Psychology and the teacher. Nova Iorque: Appleton. Recuperado de http://catalog.hathitrust.org/Record/001280239 


\section{G.Toassa}

Patto, M. H. S. (2008). A Produção do fracasso escolar: Histórias de submissão e rebeldia.( $3^{\mathrm{a}}$ ed.). São Paulo: Casa do Psicólogo. (Trabalho original publicado em 1990)

Salomão, G. L. (2008). Registros vocais no canto: Aspectos perceptivos, acústicos, aerodinâmicos e fisiológicos da voz modal e da voz falsete (Tese de Doutorado). Pontifícia Universidade Católica de São Paulo, São Paulo. Recuperado de http://www.sapientia.pucsp.br/tde_busca/arquivo. php?codArquivo $=8179$

Saviani, D. (2008). Pedagogia histórico-critica (10 $\mathrm{a}$ ed.). São Paulo: Autores Associados.

Toassa, G. (2012) Vygotsky contra James-Lange: Crítica para uma teoria históricocultural das emoções. Psicologia USP, 23(1), 91-110.

van der Veer, R., \& Valsiner, J. (2001). Vygotsky: Uma Sintese. São Paulo: Loyola/Unimarco.

Vygotsky, L. S. (1982 - 1983). Sobranie sotchinenii v chesti tomarh. (Tomos 2 e 3) Moskva: Pedagoguika.

Vygotski, L. S. (1991a). La conciencia como problema de la psicología del comportamiento (pp. 39-61). Obras escogidas (Tomo 1). Madrid: Visor. (Trabalho original proferido entre 1924-1934)
Vygotsky, L. S. (1991b) Pedagoguitcheskaya Psikhológuiya (Psicologia Pedagógica). Moskva: Pedagoguika. (Trabalho original publicado em 1926).

Vygotski, L. S. (1993). Obras escogidas (Tomo II). Madrid, Visor.

Vygotski, L. S. (1995) Historia del desarollo de las funciones psíquicas superiores. In Obras escogidas (Vol. 3, pp. 11-340). Madrid: Visor Distribuiciones. (Texto original publicado em 1931)

Vygotsky, L. S. (2001). Psicologia pedagógica. São Paulo: Martins Fontes. (Texto original publicado em 1926)

Vygotsky, L. S. (2003) Psicologia Pedagógica. Porto Alegre: Artmed. (Texto original publicado em 1926)

Vygotsky, L. S. (2010) Quarta aula: a questão do meio na pedologia. Psicologia USP, 21(4), 681-701. (Trabalho original publicado em 1935)

Vygotsky, L. S. (2007) Interação entre aprendizado e desenvolvimento. In $A$ formação social da mente (pp. 87-106). São Paulo: Martins Fontes. (Trabalho original publicado em 1935)

Yasnitsky, A. (2011) O Vygotsky que nós (não) conhecemos: Os principais trabalhos de Vygotsky e a cronologia de sua composição. (A. Delari Junior, Trad.). PsyAnima, Dubna Psychological Journal, 4(4), 62-70. Recuperado de http://www.psyanima.ru/journal/2011/4/2011n4a1/2011n4a1.2.pdf

1. Cotejou-se a edição da Artmed com o original em russo (Vygotsky, 1926/1991b; 1926/2003).

2. Note-se que a tradição socialista de crítica à opressão de gênero estava bastante viva desde Marx (1848/2003) e Engels (1884/2007). Alexandra Kolontai, Comissária da Saúde da Rússia a partir de 1918, já publicara importantes ensaios feministas, como "A nova mulher e a moral sexual" e "O amor na sociedade comunista” (Kolontai, 1918-1921/2000).

3. Vygotsky (1926/2003, p. 298) cita e aprova Münsterberg ao comentar a exigência de certo temperamento emocional inato do professor. Sustenta que, quem não é ardente ou frio, mas temperado, não poderá ser bom professor. Para incômodo do leitor socialista contemporâneo, sustenta ainda que, dada a desfavorável correlação econômica de forças, para a profissão docente confluem os desadaptados (перrisposoblennoе - неприспособленное), frustrados, os que sofreram fracassos, havendo seleção natural (estestvennii otbor - естественный отбор) de um material humano fraco, impróprio e mutilado. O termo "adaptação" é também utilizado em outros pontos do livro (pp. 92; 97), em contexto criativo, no qual Vygotsky aponta a complexidade das tendências existentes no meio social. Porém, no trecho acima comentado, o autor expressa uma compreensão mais alinhada aos equívocos do darwinismo social do que a leituras consistentes do próprio Darwin. Vygotsky deixa transparecer sua predileção normativa: depreende-se de sua fala, por exemplo, que o casamento é sinônimo de adaptação. Parece confundir conjugalidade humana e procriação animal, quando Darwin (2008, p.106) apontava claramente as diferenças entre seleção natural e sexual no mundo animal, além de compreender que, por exemplo, o "sentido da beleza" dependia da natureza da mente. Equívoco qualificável como “darwinismo social” também respingaram, para manter foco em uma autora já comentada neste artigo, em Kolontai (1918-1921/2000), ilustrando a enorme dificuldade de compreensão das ideias darwinianas, que se estende até hoje.

4. Veja-se a página 243, na qual Vygotsky defende que a garganta humana é instrumento musical por excelência, com possibilidades que superam mesmo as conquistas supremas da arte vocal. Os mais bem dotados na qualidade da voz seriam aqueles que puderam conservá-la. Entretanto, a despeito de poder alterar-se significativamente com aprimoramento e fonoterapia, sabemos hoje que a qualidade vocal tem limites determinados pela anatomia e fisiologia dos órgãos fonoarticulatórios do falante, conforme indica Salomão (2008, p. 56) ao comentar Abercrombie.

5. No Tomo III (Vygotsky, 1982-1983): contaram-se 538 ocorrências do núcleo no peакц, "Historia del desarrollo de las funciones psiquicas superiores", que, como afirma Yasnitsky (2011), tem partes que se assemelham à terminologia reactológica dos anos 1920. Excetuando-se as 46 no posfácio de Matiushkin, índice remissivo e comentários, o total de vezes que aparece no texto Vygotskyanos é de 492, com utilização da ferramenta de busca do Advanced Search do Adobe. No Tomo II, excetuando-se o posfácio de Luria e os comentários (pp. 468;488) são 79 as ocorrências, 33 delas no "Pensamento e linguagem" e 46 nas conferências sobre psicologia. Mas o termo não aparece sequer no índice remissivo de Vygotsky (1993).

6. Para Vygotski (1931/1995, p. 145) a geologia da conduta (e sua integração mais abrangente na consciência) humana torna-se, num certo sentido, reflexo da origem geológica e do desenvolvimento do cérebro, com estruturas que amadurecem - eis a natureza fundamental do desenvolvimento biológico - e formam hierarquias integradoras de várias zonas funcionais (1924-1934/1991a, p. 135). 
7. Consulta ao Dicionário Yandex (Yandex Slovari, s/d) mostra o termo realnaia deistvitelnost (реальная действительность). Embora a tradução de Vygotsky (1926/2003, p.77) não se mostre inadequada, outras possíveis traduções seriam o pleonasmo "realidade real" ou "prática", "efetiva", "atual” (Vygotsky, 1926/1991b, p. 85). Parece-nos que Vygotsky fala da vida em seu caráter geral e multideterminado, ultrapassando a realidade mais simples e particular da escola.

8. Neste aspecto, sobressai a influência de Blonski (como evidencia-se em Danilchenko, 1993). Pavel Petrovich Blonski (1884-1941) foi influência importante na obra Vygotskyana - ministrou os únicos cursos de psicologia que Vygotsky frequentou em sua graduação, na Universidade de Moscou - embora tenhamos ainda que avaliar a exata extensão dessa influência.

9. Embora faça referência à psicanálise, note-se que Vygotsky não anota diferença entre neurose e perversão (sendo ambos os conceitos bastante precoces na história da psicanálise).

Gizele Toassa, doutora em Psicologia Escolar e do Desenvolvimento Humano, Instituto de Psicologia, Universidade de São Paulo (USP), é professora adjunta na Faculdade de Educação da Universidade Federal de Goiás. Endereço: R. 236, n.375, apto 502, Setor Leste Universitário, Goiânia, GO. Telefones: (62) 36422502/8174-2502. E-mail: gtoassa@gmail.com 